\title{
Intensive Care Management of Acute Liver Failure: Considerations While Awaiting Liver Transplantation
}

\author{
Anil Seetharam* \\ Transplant and Advanced Liver Disease Center, University of Arizona College of Medicine, Phoenix, AZ, USA
}

\begin{abstract}
Acute liver failure is a unique clinical phenomenon characterized by abrupt deterioration in liver function and altered mentation. The development of high-grade encephalopathy and multisystem organ dysfunction herald poor prognosis. Etiologic-specific treatments and supportive measures are routinely employed; however, liver transplantation remains the only chance for cure in those who do not spontaneously recover. The utility of artificial and bioartificial assist therapies as supportive care-to allow time for hepatic recovery or as a bridge to liver transplantation-has been examined but studies have been small, with mixed results. Given the severity of derangements, intensive critical care is needed to successfully bridge patients to transplant, and evaluation of candidates occurs rapidly in parallel with serial reassessments of operative fitness. Psychosocial assessment is often suboptimal and relative contraindications to transplant, such as ventilator-dependence may be overlooked. While often employed to guide evaluation, no single prognostic model discriminates those who will spontaneously recover and those who will require transplant. The purpose of this review will be to summarize approaches in critical care, prognostic modeling, and medical evaluation of the acute liver failure transplant candidate.
\end{abstract}

Citation of this article: Seetharam A. Intensive care management of acute liver failure: Considerations while awaiting liver transplantation. J Clin Transl Hepatol 2019;7(4):384391. doi: 10.14218/JCTH.2019.00032.

\section{Introduction}

Acute liver failure (ALF) is an infrequent condition in which rapid deterioration of liver function results in altered mentation and coagulopathy in individuals without pre-existing liver disease. ${ }^{1}$ Approximately 2,000 cases are thought to occur in the USA annually. ${ }^{2}$ Studies estimating ALF prevalence and incidence in the European Union are lacking; however,

Keywords: Acute liver failure; Thromboelastography; Intracranial hypertension; Liver assist therapy; Transplantation.

Abbreviations: ALF, acute liver failure; CPP, cerebral perfusion pressure; $\mathrm{ICH}_{\text {, }}$ intracranial hypertension; ICP, intracranial pressure; ICU, intensive care unit INR, international normalized ratio; KCC, King's College Criteria; LT, liver transplantation; MAP, mean arterial pressure; MELD, model for end-stage liver disease; NAC, N-acetylcysteine; rFVIIa, recombinant activated factor seven.

Received: 31 July 2019; Revised: 6 October 2019; Accepted: 27 October 2019 *Correspondence to: Anil Seetharam, Banner Transplant and Advanced Liver Disease, University of Arizona College of Medicine, 441 N. 12th Street, $2 \mathrm{nd}$ Floor, Phoenix, AZ 85006, USA. Tel: +1-602-521-5800; Fax: +1-602-521-5337, E-mail: Anil.Seetharam@bannerhealth.com review of the European Liver Transplant Registry identified ALF as the primary indication for transplant in only $8 \%$ of transplants performed over a 20-year period. ${ }^{3,4} \mathrm{~A}$ key element in identifying ALF is the absence of preexisting liver disease (distinguishing it from acute-on-chronic liver disease) and international societies have guided definitions for severity of liver injury. ${ }^{5}$

A widely accepted working definition of ALF includes: an international normalized ratio (INR) $>1.5$ and any degree of mental alteration (encephalopathy) in a subject without preexisting cirrhosis and with illness of $<26$ weeks' duration. ${ }^{6}$ Currently, overall short-term survival (2 years) in those undergoing transplantation approaches $90 \% .^{7}$ Liver transplantation (LT) remains the only definitive treatment for subjects who fail to spontaneously recover or respond to etiology-specific medical therapy. Moreover, patients are often managed in an intensive care unit (ICU) setting while awaiting LT. The approach to the diagnostic evaluation of ALF has been described elsewhere. ${ }^{8,9}$ The purpose of this review will be to summarize recent advances in critical care management, prognostic modeling, and evaluation of the ALF transplant candidate.

\section{Etiology-specific therapy}

Etiology-specific treatment for ALF is often administered in an ICU setting (Table 1 ). ${ }^{10}$ Both acetaminophen and non-acetaminophen drug-induced liver injury, acute viral hepatitis, autoimmune hepatitis, Wilson's Disease, and vascular disorders represent examples for which etiology-specific therapy can be attempted to regain parenchymal function. ${ }^{11}$

In instances of known or suspected acetaminophen ingestion, $\mathrm{N}$-acetylcysteine (NAC) can be given as an antidote orally or intravenously; its efficacy and safety is well-established. ${ }^{12,13}$ NAC should be given as early as possible, most commonly via intravenous administration (loading dose of $150 \mathrm{mg} / \mathrm{kg}$ in $5 \%$ dextrose over $15 \mathrm{~m}$; maintenance dose of $50 \mathrm{mg} / \mathrm{kg}$ given over $4 \mathrm{~h}$, followed by $100 \mathrm{mg} / \mathrm{kg}$ administered over $16 \mathrm{~h}$ or $6 \mathrm{mg} / \mathrm{kg} / \mathrm{h}$ ) but may have value $48 \mathrm{~h}$ or more after ingestion. ${ }^{14}$ At this time, there is no consensus as to whether a standard 72-h period is optimal or the further continuation based on clinical course. Medications other than acetaminophen may be implicated as the causative agent for ALF. ${ }^{15}$ These are generally thought to represent examples of idiosyncratic drug hepatotoxicity. Investigation has suggested that a course of NAC (dosage outlined above) may abrogate non-acetaminophen-related drug-induced liver injury. ${ }^{16}$ In a recent randomized case-control study of 80 subjects with non-acetaminophen-induced liver failure, use of NAC was associated with a significantly lower mortality 
Table 1. Etiology-specific therapies for ALF. Directed therapy of ALF when etiology is known may increase transplant-free survival.

\begin{tabular}{|c|c|}
\hline Etiology & Therapy $^{a}$ \\
\hline $\begin{array}{l}\text { Acetaminophen and } \\
\text { non-acetaminophen } \\
\text { drug-induced liver } \\
\text { injury }\end{array}$ & $\begin{array}{l}\text { NAC: loading dose is } 150 \\
\mathrm{mg} / \mathrm{kg} \text { in } 5 \% \text { dextrose over } \\
15 \mathrm{~m} \text {; maintenance dose is } \\
50 \mathrm{mg} / \mathrm{kg} \text { given over } 4 \mathrm{~h} \\
\text { followed by } 100 \mathrm{mg} / \mathrm{kg} \\
\text { administered over } 16 \mathrm{~h} \text { or } 6 \\
\mathrm{mg} / \mathrm{kg} / \mathrm{h}\end{array}$ \\
\hline Hepatitis B & $\begin{array}{l}\text { Antiviral therapy with } \\
\text { nucleos(t)ide analogue: } \\
\text { entecavir or tenofovir }\end{array}$ \\
\hline $\begin{array}{l}\text { Herpes (herpes simplex } \\
\text { virus) }\end{array}$ & $\begin{array}{l}\text { Acyclovir } 5-10 \mathrm{mg} / \mathrm{kg} \\
\text { intravenous every } 8 \mathrm{~h} \text { for at } \\
\text { least } 7 \text { days }\end{array}$ \\
\hline Autoimmune hepatitis & $\begin{array}{l}\text { Prednisone } 40-60 \mathrm{mg} \text { PO } \\
\text { daily }\end{array}$ \\
\hline Wilson's disease & $\begin{array}{l}\text { Albumin dialysis, } \\
\text { continuous hemofiltration, } \\
\text { plasmapheresis, or plasma } \\
\text { exchange }\end{array}$ \\
\hline Budd-Chiari syndrome & $\begin{array}{l}\text { Attempts at hepatic vein } \\
\text { recanalization with } \\
\text { transjugular or direct } \\
\text { portosystemic shunt; } \\
\text { systemic anticoagulation }\end{array}$ \\
\hline $\begin{array}{l}\text { Mushroom Poisoning } \\
\text { (Aminita phalloides) } \\
\text { ingestion }\end{array}$ & $\begin{array}{l}\text { Gastric lavage, activated } \\
\text { charcoal } \\
\text { NAC; silymarin }\end{array}$ \\
\hline $\begin{array}{l}\text { Acute fatty liver of } \\
\text { pregnancy }\end{array}$ & Delivery of the fetus \\
\hline
\end{tabular}

a Etiology-directed therapy is administered concomitantly with intensive care support and medical evaluation for transplant.

Abbreviations: ALF, acute liver failure; NAC, N-acetylcysteine.

( $28 \%$ in NAC group vs. $53 \%$ control, $p=0.02$ ) and shorter length of stay. ${ }^{17}$

Acute viral hepatitis acquisition with hepatitis $A, B, D$ or $E$ may progress to $\mathrm{ALF}^{7}$ In instances of serologically identified hepatitis $A$ and $E$, management is largely supportive. Nucleos (t)ide analogue therapy can be attempted in acute hepatitis $B$ or $D$; however, reversal of severe injury with early agents (e.g. lamivudine) has rarely been achieved. ${ }^{18}$ Improved efficacy has been reported with new-generation therapy (entecavir and tenofovir); a recent investigation found higher short-term efficacy with tenofovir in cases of acute-onchronic liver failure with suspected hepatitis B virus reactivation. ${ }^{19}$ Herpes virus infection is an uncommon cause of ALF but has been reported in both immunocompromised and immunocompetent subjects. ${ }^{20,21}$ Empiric treatment should be considered utilizing acyclovir (5-10 mg/kg every $8 \mathrm{~h}$ for at least 7 days). Cytomegalovirus, varicella-zoster, EpsteinBarr, and adenovirus have all been reported as viral causes of ALF, albeit rare, particularly in pediatric or immunocompromised populations. ${ }^{22-24}$

Autoimmune hepatitis may present with ALF. ${ }^{6}$ Initiation of steroid therapy may be considered for some patients (prednisone starting at $40-60 \mathrm{mg} /$ day). However, in some patients this may be deleterious, and transplant evaluation should not be delayed while awaiting a response. ${ }^{25}$

Wilson's disease, an inherited metabolic disorder in copper transport, is a relatively infrequent cause of ALF. ${ }^{26}$ This fulminant presentation is considered uniformly fatal without transplantation. Treatment to acutely lower serum copper and to limit further hemolysis can include albumin dialysis, continuous hemofiltration, plasmapheresis, or plasma exchange; ${ }^{6}$ although, such copper lowering measures can be employed, recovery is very rare without $\mathrm{LT}^{27}$

Vascular disorders of the liver may also be associated with ALF. Budd-Chiari syndrome, characterized by acute hepatic outflow obstruction, may precipitate severe acute liver injury requiring consideration of hepatic vein recanalization or shunting; preexisting hypercoagulable state must be investigated and mandates treatment with systemic anticoagulation. ${ }^{28}$ Acute ischemic injury to the liver may cause ALF, typically in patients with preexisting cardiac dysfunction rendering hepatic tissue sensitive to minor reductions in systolic blood pressure-treatment in these instances generally focuses on restoration of normal hemodynamics.

Mushroom poisoning (most commonly associated with Aminita phalloides) may cause ALF. Typically, gastrointestinal symptoms including profuse vomiting and diarrhea occur after mushroom ingestion. Gastric lavage, supportive measures, as well as various agents with antidotal properties (benzylpenicllin, NAC, silymarin) can be considered. ${ }^{29}$

Acute fatty liver of pregnancy is characterized by extensive steatosis in the third trimester of pregnancy. Development, in part, is related to inheritance patterns in mother and fetus, particularly of long-chain 3-hydroxylacyl-CoA dehydrogenase (also referred to as LCHAD) deficiency, which is linked to fetal fatty oxidation defects. ${ }^{30}$ Prompt delivery of the fetus is the preferred management and often reverses liver injury.

\section{Coagulopathy}

In ALF, prothrombin time and its derivative INR are elevated and are considered predictors of increased bleeding riskthough magnitude of effect is undefined. Previous investigation has found a concomitant and proportional reduction in plasma levels of both procoagulants and natural anticoagulant proteins, in conjunction with a significant elevation in plasma levels of factors-VIII (referred to as FVIII) and Von Willebrand factor, culminating in an overall efficient, albeit reduced, thrombin generation capacity in comparison with healthy individuals. ${ }^{31}$ Global hemostasis as assessed with thromboelastography may be normal by several compensatory mechanisms, even in patients with markedly elevated INR. ${ }^{32}$ In the absence of overt bleeding, measures to correct the INR with plasma are not recommended and may potentially obscure trends marking prognosis. ${ }^{6}$

Vitamin $\mathrm{K}$ deficiency has been reported in patients with $\mathrm{ALF}^{33}$ and vitamin K (10 mg subcutaneously) can be administered (Table 2). Treatment of clotting factor deficiency is generally reserved for clinically significant bleeding or in preparation for a high-risk invasive procedure (e.g., intracranial pressure (ICP) monitor placement). Fresh frozen plasma infusion alone infrequently corrects a severely elevated INR and carries risk of volume overload and transfusion-related lung injury. ${ }^{34}$ Use of recombinant activated factor seven (referred to as rFVIIa) may be considered, as administration in combination with frozen fresh plasma provides temporary correction of coagulopathy without volume overload. ${ }^{35,36}$ Important 
barriers to the rFVIIa utilization include availability, cost, and reports of thromboembolic phenomenon. ${ }^{37}$ There is no consensus regarding the prophylactic administration of platelets in thrombocytopenic patients with ALF and this is generally reserved for cases of overt bleeding or prior to invasive procedures. $^{6}$

\section{Circulatory dysfunction/renal failure}

ALF, similar to cirrhosis or sepsis, is characterized by low systemic vascular resistance. Diminished tone may compromise peripheral tissue oxygenation and promote multisystem organ failure. Maintenance of adequate mean arterial pressure (referred to as MAP) is of particular importance in ALF subjects with increased ICP to maintain cerebral perfusion pressure (CPP) [CPP equates to MAP minus ICP]. Intravascular volume depletion is common at ALF presentation and resuscitation is often required. Hypotensive patients with ALF should be resuscitated with normal saline and changed to half-normal saline containing $75 \mathrm{mEq} / \mathrm{L}$ sodium bicarbonate if acidotic. ${ }^{38}$ Volume expanding solutions should contain dextrose to prevent hypoglycemia if present. ${ }^{39}$

Subjects remaining hypotensive despite volume resuscitation should be cultured for infection and considered for vasopressor support to maintain a MAP of at least $75 \mathrm{mmHg}$ or a CPP of $60-80 \mathrm{mmHg} .{ }^{38}$ While no studies have defined the optimal vasopressor, norepinephrine is known to augment peripheral organ perfusion while minimizing tachycardia and preserving splanchnic/hepatic blood flow. ${ }^{40}$ Vasopressin and/ or analogues may potentiate effects of norepinephrine and allow a decrease in its infusion rate, mitigating intense vasoconstriction in peripheral tissues that may lead to bowel and/ or limb ischemia. ${ }^{6}$
Seetharam A.: Liver transplantation for acute liver failure

Independent of vascular resistance, relative adrenal insufficiency has been commonly observed in over half of patients presenting with ALF. ${ }^{41}$ Although a mortality benefit with hydrocortisone usage in ALF subjects has not been demonstrated, utility as an adjunctive measure to reduce systemic vasopressor requirement has been demonstrated. ${ }^{42}$ Use of corticosteroids in the context of ALF must be individualized, taking into account etiology of liver injury and risk of infection.

Substantial renal dysfunction (either functional or as a result of acute tubular necrosis) may occur in greater than $50 \%$ of patients with $\mathrm{ALF}^{8}$ Acute kidney injury more commonly occurs when acetaminophen is the etiology of injury and in the elderly. ${ }^{43}$ Renal failure contributes to morbidity and mortality and is associated with a poorer prognosis. ${ }^{44}$ When support is required, continuous renal replacement therapy is preferred over conventional hemodialysis, as the former has been shown in randomized trials to result in improved stability in cardiovascular and intracranial parameters compared to the latter. ${ }^{45}$ Avoidance of nephrotoxic agents, including intravenous contrast agents, is standard of care. ${ }^{6}$

\section{Encephalopathy/ICP management}

Cerebral edema and intracranial hypertension (ICH) represent the most serious complications of ALF. ${ }^{46}$ Although pathogenesis is only partly understood, there is evidence that both systemic and local inflammation and circulating neurotoxins, including ammonia, play roles. ${ }^{47}$ Ammonia infusion causes brain edema in animal models, and an arterial ammonia level $>200 \mu \mathrm{g} / \mathrm{dL}$ in humans is strongly associated with cerebral herniation. ${ }^{48,49}$ Encephalopathy can be precipitated by infection or may occur as a result of low systemic blood

Table 2. Organ-specific supportive measures for ALF in the intensive care unit. Supportive measures to address multisystem organ dysfunction occurring in ALF generally requires intensive critical care.

\begin{tabular}{|c|c|c|}
\hline Organ system & Derangement & Supportive measures \\
\hline Hematologic & $\begin{array}{l}\text { Concomitant and proportional reduction in both } \\
\text { procoagulants and anticoagulants } \\
\text { Significant elevation in plasma levels of factors-VIII } \\
\text { (FVIII) and Von Willebrand factor } \\
\text { Reduced thrombin generation capacity }\end{array}$ & $\begin{array}{l}\text { Vitamin } \mathrm{K} 10 \mathrm{mg} \text { intravenous } \times 1 \text { considered in those } \\
\text { with nutritional deficiency } \\
\text { Fresh frozen plasma, platelets, and rFVIII reserved } \\
\text { for active bleeding or invasive procedure }\end{array}$ \\
\hline Cardiovascular & $\begin{array}{l}\text { Low systemic vascular resistance } \\
\text { Diminished tone compromising peripheral tissue } \\
\text { oxygenation }\end{array}$ & $\begin{array}{l}\text { Hypotensive patients resuscitated with normal } \\
\text { saline and changed to half-normal saline containing } \\
75 \mathrm{mEq} / \mathrm{L} \text { sodium bicarbonate if acidotic } \\
\text { Volume expanding solutions with dextrose to } \\
\text { prevent hypoglycemia } \\
\text { Vasopressor (norepinephrine) support to maintain a } \\
\text { mean arterial pressure }>75 \mathrm{mmHg} \text { or a cerebral } \\
\text { perfusion pressure of } 60-80 \mathrm{mmHg}\end{array}$ \\
\hline Renal & $\begin{array}{l}\text { Prerenal kidney injury from diminished effective } \\
\text { circulating volume, acute tubular necrosis, or } \\
\text { reduced function }\end{array}$ & $\begin{array}{l}\text { Continuous renal replacement therapy preferred } \\
\text { over conventional hemodialysis }\end{array}$ \\
\hline Neurologic & $\begin{array}{l}\text { Systemic and local inflammation and circulating } \\
\text { neurotoxins, including ammonia that promote } \\
\text { cerebral edema and intracranial hypertension }\end{array}$ & $\begin{array}{l}\text { Consideration of intracranial monitor placement } \\
\text { Head of bed elevation } \\
\text { Avoid endotracheal suction } \\
\text { Mannitol }\end{array}$ \\
\hline
\end{tabular}

${ }^{\mathrm{a}}$ Intracranial pressure monitoring placement is variable and based on center expertise.

Abbreviation: ALF, acute liver failure. 
pressure and vasodilatation. ${ }^{50}$ Incidence of cerebral edema and ICH in ALF is directly related to severity of hepatic encephalopathy, with episodes of ICH occurring between $65-75 \%$ in those with the highest grade. ${ }^{51}$

As patients progress to higher grades of encephalopathy, intubation and mechanical ventilation are mandatory for airway protection. Propofol is routinely chosen for sedation because it may reduce cerebral blood flow. ${ }^{52}$ Frequent neurological evaluation for signs of ICH (e.g., sluggish pupillary reflexes and posturing) should be conducted. To reduce the incidence of $\mathrm{ICH}$, patients should have the head elevated at 30 degrees and stimulation (including endotracheal suctioning) and pain should be minimized. 6,53

Invasive and noninvasive monitoring strategies have been utilized to assess progression of cerebral edema. ${ }^{54}$ Use of ICP monitoring devices is controversial but employed by many ICUs. The principal concern is for intracranial hemorrhage with ICP placement, particularly in ALF subjects with advanced encephalopathy and active infection. Experience is limited with noninvasive strategies, such as transcranial Doppler, jugular bulb oximetry, and pupillometry. ${ }^{55}$ If ICP monitoring is performed, both ICP and CPP are followed with a goal ICP below $20-25 \mathrm{mmHg}$ and CPP maintained above $50-60 \mathrm{mmHg}$. ${ }^{56}$

Based on the role of arterial ammonia in pathogenesis, investigation has focused on the use of lactulose administration in ALF. In a study of ALF patients who received lactulose compared to a matched group of patients who did not, a small increase in survival time was seen in those receiving lactulose, but there was no difference in the severity of encephalopathy or outcome. ${ }^{57}$ One concern regarding the use of lactulose in this setting is the precipitation of bowel gas with excessive usage, thereby complicating subsequent transplant surgery. ${ }^{11}$

Osmotic agents, such as mannitol, can be effective in decreasing cerebral edema. ${ }^{58}$ Mannitol was found to transiently correct episodes of elevated ICP in ALF patients and also to improve survival. ${ }^{59}$ Administration of intravenous mannitol (in a bolus dose of $0.5-1.0 \mathrm{~g} / \mathrm{kg}$ ) is recommended as first-line therapy of ICH in patients with ALF but repeated doses may trigger serum hyperosmolality. ${ }^{6}$ In patients with ALF and severe hepatic encephalopathy, a controlled trial of the prophylactic induction of hypernatremia with hypertonic saline (to a serum sodium $145-155 \mathrm{mEq} / \mathrm{L}$ ) suggested a lower incidence of $\mathrm{ICH}^{60}$ Utilization of hypertonic saline as treatment for established ICH has not been studied. Barbiturate agents (thiopental or pentobarbital) may also be considered to decrease ICP that has been nonresponsive to other measures. ${ }^{61}$ Significant systemic hypotension may limit use and may necessitate vasopressor administration to maintain adequate mean arterial pressure. In addition, barbiturate clearance is markedly reduced in patients with ALF, potentially confounding neurological assessments. Hypothermia may prevent or control ICH in patients with ALF. ${ }^{62}$ Pilot studies suggest potential use (core temperature of $33-34{ }^{\circ} \mathrm{C}$ ) as a bridge to LT. ${ }^{63}$ Induced hypothermia has not been compared to normothermic conditions in a controlled trial and there is theoretical concern about a negative effect on hepatic regeneration. ${ }^{64}$

\section{Advanced systems}

Over the years, several artificial and bioartificial liver assist therapies have been tested for utility as supportive care to allow time for hepatic recovery or as a bridge to LT. ${ }^{65}$ Owing to the relative rarity of the condition, clinical heterogeneity and complexity in administration, studies have been small with mixed results. In the FULMAR trial examining use of an extracorporeal device in patients with ALF, there was no improvement in overall survival in the cohort but there was a trend of potential benefit in patients with acetaminophen as the etiology of ALF. ${ }^{66}$ Therapeutic plasma exchange has hypothesized applicability in ALF through removal of inhibitors of hepatic regeneration. In a multicenter randomized controlled trial, three 5-I sessions of therapeutic plasma exchange significantly improved survival, although the survival benefit was inferior to that seen with transplantation. ${ }^{67}$ Other forms of cellular therapy (including hepatocyte transplantation) have showed potential as future treatments for ALF but are not ready for routine clinical practice. ${ }^{68-70}$ Recent society guidelines suggest consideration of available support systems in patients with ALF with an expected poor prognosis without transplantation but who have clear medical or psychiatric contraindications to surgery. ${ }^{3}$

\section{Prognostic models}

A number of different systems are in current worldwide use to assess prognosis in patients with ALF (Table 3). ${ }^{71-73}$ All systems utilize admission laboratory measures (coagulopathy of highest weight) and recognize the development of encephalopathy and advanced age as markers of poor prognosis. One of the oldest and most utilized tools are the King's College Criteria (KCC), the original iteration now used for 3 decades, being the first to recognize the importance of etiology of ALF/acetaminophen toxicity carrying higher chance of recovery than others. ${ }^{74}$ With over 3 decades of utilization, the KCC is noted to have high specificity (relatively few cases fulfilling criteria would be 'unnecessarily transplanted'); however, it suffers from relatively low sensitivity (significant number of cases not fulfilling criteria would progress and die without earlier identification and consideration of LT). The latest model from the King's College is a dynamic outcome prediction model and has been validated for use with ALF from acetaminophen toxicity. ${ }^{75}$ The model uses a number of clinical variables sequentially assessed from admission to $72 \mathrm{~h}$ and has demonstrated good discrimination between survivors and non-survivors.

Recently, the United States Acute Liver Failure Group prospectively enrolled over 1900 subjects with ALF, managed with and without transplantation. ${ }^{76}$ Investigators aimed to develop a model for ALF (all etiologies included) to predict transplant-free survival at 21 days. Clinical demographics and laboratory values were collected at enrollment and recorded serially up to 1 week. Variables of prognostic value adopted in the predictive model included admission coma grade, ALF etiology and vasopressor requirement, and admission INR and bilirubin values. The model correctly predicted outcome of illness in $66.3 \%$ of subjects, slightly outperforming $\mathrm{KCC}$ and the model for end-stage liver disease (referred to as MELD) score. Performance appeared best in patients with non-acetaminophen etiology and high-grade encephalopathy.

A number of other scoring systems have been proposed to identify candidates most at risk for death and need for LT. Non-liver specific indices, such as the sequential organ failure assessment which is widely used to quantify severity of multiorgan failure in other forms of critical illness, have 
Seetharam A.: Liver transplantation for acute liver failure

Table 3. Prognostic models for ALF. Evaluation of various prognostic scoring systems in ALF cohorts.

\begin{tabular}{|c|c|c|c|c|c|c|c|}
\hline Study & $\begin{array}{l}\text { Prognostic } \\
\text { model }\end{array}$ & $\begin{array}{l}\text { ALF } \\
\text { etiology }\end{array}$ & $\begin{array}{l}\text { Subjects } \\
\text { studied, } n\end{array}$ & $\begin{array}{l}\text { Subjects died or } \\
\text { transplanted }\end{array}$ & Sensitivity & Specificity & AUROC \\
\hline $\begin{array}{l}\text { McPhail } \\
\text { et al. }{ }^{79}\end{array}$ & $\mathrm{KCC}$ & All & 2153 & Unknown & 0.55 & 0.79 & 0.76 \\
\hline $\begin{array}{l}\text { McPhail } \\
\text { et al. }{ }^{79}\end{array}$ & MELD & All & 2153 & Unknown & 0.74 & 0.67 & 0.78 \\
\hline Koch et al. ${ }^{76}$ & ALFSG & All & 1974 & $987(50 \%)$ & $\begin{array}{l}\text { Not } \\
\text { reported }\end{array}$ & $\begin{array}{l}\text { Not } \\
\text { reported }\end{array}$ & 0.84 \\
\hline $\begin{array}{l}\text { Cholongitas } \\
\text { et } a .^{78}\end{array}$ & SOFA & $\begin{array}{l}\text { APAP } \\
\text { only }\end{array}$ & 125 & $58(46 \%)$ & 0.67 & 0.80 & 0.79 \\
\hline
\end{tabular}

Abbreviations: ALF, acute liver failure; ALFSG, Acute Liver Failure Study Group; APAP, acetaminophen; AUROC, area under the receiver operating curve; KCC, King's College Criteria; MELD, model for end-stage liver disease score; SOFA, sequential organ failure assessment score.

been utilized with comparable performance to KCC in prediction of non-survival; although, their organ "non-specificity" compromises applicability in determining benefit with LT and use is limited. ${ }^{77,78}$ The MELD score, widely used for liver prioritization/allocation in chronic liver disease, has been investigated in ALF with similar performance to that of the $\mathrm{KCC}^{79}$ An emerging theme in ALF prognostication is the need for individualized, dynamic assessments as opposed to historically static ones at presentation. An investigation utilizing the ALF early dynamic model followed clinical variables over 3 days and outperformed KCC and MELD in predicting outcome in an observational study of 380 subjects. ${ }^{80}$

Recently, investigation has focused on the use of biomarkers in prediction of outcome with ALF. Circulating blood levels of caspase-cleaved and uncleaved cytokeratin K18 (referred to as CK18), an apoptosis cell death marker, has shown promise. ${ }^{81}$ Subjects with spontaneous recovery of ALF have been demonstrated to have higher level of caspase activation than in subjects who required transplant or died. ${ }^{82} \mathrm{Cir}-$ culating levels in concert with standard blood measures of coagulation and renal function demonstrated superior sensitivity and specificity to KCC in predicting ALF outcome; although, further studies are needed. ${ }^{83}$ HLA-DR monocyte expression has been identified as a potential biomarker of ALF severity and outcome in acetaminophen-related ALF. ${ }^{84}$

\section{Transplant evaluation and listing}

While advances in critical care have improved survival with ALF, LT remains the standard of care for those with progressive injury. ${ }^{85}$ Given the severity of injury, multisystem organ dysfunction, and encephalopathy, the usual protocol for candidate evaluation is accelerated. Psychosocial assessment of the potential recipient may be challenging, as ALF patients with advanced stages of hepatic encephalopathy may be unable to respond to direct questioning. Candidate interview is often suboptimal, with collateral information often garnered from historical chart review and interview of available friends and family. ${ }^{86}$ Assessment of critical issues, such as adherence and social support, is often speculative. In certain cases of ALF, individual centers may overlook traditional contraindications to LT, such as alcohol abuse, drug use or suicide attempt; as such, the decision to deny or support transplant listing should be done involving activation of a multidisciplinary transplant team with thorough documentation of decision-making. ${ }^{87}$
A number of shortcomings may be present despite thorough evaluation. Living donor donation for ALF (particularly in areas of the world where access to cadaveric grafts may be low) raises ethical concern of coercion for potentially compatible family members. In addition, given the acuity of illness and associated multisystemic organ dysfunction, determining futility or when the patient is too sick to transplant may be a clinical challenge, as widely accepted relative contraindications to LT (bacteremia or ventilatory-dependent respiratory failure) may be overlooked if responding to critical care measures.

Adult ALF subjects who meet program criteria for listing in the USA are granted status $1 \mathrm{~A}$, placing the patient at the highest priority on the waiting list. In order to be listed as status $1 \mathrm{~A}$, the ALF candidate must be at least 18 years-old, with life expectancy of less than 7 days. Additionally, he or she must be in the ICU and meet at least 1 of the following criteria: 1 ) ventilator dependence; 2 ) requiring renal replacement therapy; 3) INR greater than 2.0.88 The mean time between listing and LT is 2 days in the USA. ${ }^{89}$

Currently, ALF accounts for approximately $8 \%$ of all liver transplants, as per data from the Scientific the Registry of Transplant Recipients and the European Liver Transplant Registry, with 1 -year survival rates of $84 \%$ in the USA and $79 \%$ in Europe, respectively. ${ }^{4,90}$ Outcomes are inferior when compared with patients receiving a transplant due to chronic liver disease; though survival rates even out beyond 1 year. ${ }^{91}$ In a series of over 1400 patients from the United Network for Organ Sharing database of LT for ALF, body mass index greater than 30, serum creatinine greater than $2 \mathrm{mg} / \mathrm{dL}$, recipient age greater than 50 years, and a history of life support were independent factors of poor post-transplant outcomes, with a survival of less than $50 \%$ in recipients with all factors pretransplant. ${ }^{92}$ An analysis of the European Liver Transplant Registry identified male gender, older age of the donor ( $>60$ years-old), older age of the recipient (>50 years-old), incompatible graft, and reduced graft size as predictors of poor prognosis. ${ }^{4}$

\section{Conclusions}

ALF represents abrupt deterioration in hepatic function from diverse etiologies. Associated multisystem organ dysfunction and dense encephalopathy with chance for progression to brainstem herniation mandates prompt recognition and transfer to a liver transplant center. While etiologic-specific 
treatments and a number of systemic supportive measures can be employed, LT remains the only chance for cure in those who do not spontaneously recover. While often employed to guide evaluation, no single prognostic model discriminates those who will spontaneously recover and those who will require transplant. Given the severity of derangements, intensive critical care is needed to bridge ALF patients to transplant; furthermore, evaluation of potential candidates must occur rapidly and in the context of serial reassessment of fitness for surgery.

\section{Conflict of interest}

The author has no conflict of interest related to this publication.

\section{Author contributions}

Contributed to data review and writing of manuscript (AS).

\section{References}

[1] Mendizabal M, Silva MO. Liver transplantation in acute liver failure: A challenging scenario. World J Gastroenterol 2016;22:1523-1531. doi: 10. 3748/wjg.v22.i4.1523

[2] Lee WM, Squires RH Jr, Nyberg SL, Doo E, Hoofnagle JH. Acute liver failure: Summary of a workshop. Hepatology 2008;47:1401-1415. doi: 10 . 1002/hep.22177.

[3] Wendon J, Cordoba J, Dhawan A, Larsen FS, Manns M, Samuel D, et al. EASL Clinical Practical Guidelines on the management of acute (fulminant) liver failure. J Hepatol 2017;66:1047-1081. doi: 10.1016/j.jhep.2016.12.003.

[4] Germani G, Theocharidou E, Adam R, Karam V, Wendon J, O'Grady J, et al. Liver transplantation for acute liver failure in Europe: outcomes over 20 years from the ELTR database. J Hepatol 2012;57:288-296. doi: 10.1016/j.jhep. 2012.03.017.

[5] Sarin SK, Choudhury A, Sharma MK, Maiwall R, Al Mahtab M, Rahman S, et al. Acute-on-chronic liver failure: consensus recommendations of the Asian Pacific association for the study of the liver (APASL): an update. Hepatol Int 2019;13:353-390. doi: 10.1007/s12072-019-09946-3.

[6] Lee WM, Stravitz RT, Larson AM. Introduction to the revised American Association for the Study of Liver Diseases Position Paper on acute liver failure 2011. Hepatology 2012;55:965-967. doi: 10.1002/hep. 25551.

[7] Fontana RJ, Ellerbe C, Durkalski VE, Rangnekar A, Reddy RK, Stravitz T, et al. Two-year outcomes in initial survivors with acute liver failure: results from a prospective, multicentre study. Liver Int 2015;35:370-380. doi: 10. 1111/liv.12632.

[8] Wang DW, Yin YM, Yao YM. Advances in the management of acute liver failure. World J Gastroenterol 2013;19:7069-7077. doi: 10.3748/wjg.v19. i41.7069.

[9] Squires JE, McKiernan P, Squires RH. Acute liver failure: An update. Clin Liver Dis 2018;22:773-805. doi: 10.1016/j.cld.2018.06.009.

[10] Bernal W, Auzinger G, Dhawan A, Wendon J. Acute liver failure. Lancet 2010; 376:190-201. doi: 10.1016/S0140-6736(10)60274-7.

[11] Bernal W, Wendon J. Acute liver failure. N Engl J Med 2013;369:2525-2534. doi: $10.1056 /$ NEJMra1208937.

[12] Smilkstein MJ, Knapp GL, Kulig KW, Rumack BH. Efficacy of oral N-acetylcysteine in the treatment of acetaminophen overdose. Analysis of the national multicenter study (1976 to 1985). N Engl J Med 1988;319:1557-1562. doi: 10.1056/NEJM198812153192401.

[13] Keays R, Harrison PM, Wendon JA, Forbes A, Gove C, Alexander GJ, et al. Intravenous acetylcysteine in paracetamol induced fulminant hepatic failure: a prospective controlled trial. BMJ 1991;303:1026-1029. doi: 10.1136/bmj. 303.6809.1026.

[14] Harrison PM, Keays R, Bray GP, Alexander GJ, Williams R. Improved outcome of paracetamol-induced fulminant hepatic failure by late administration of acetylcysteine. Lancet 1990;335:1572-1573. doi: 10.1016/0140-6736 (90) $91388-q$.

[15] Rockey DC, Seeff LB, Rochon J, Freston J, Chalasani N, Bonacini M, et al. Causality assessment in drug-induced liver injury using a structured expert opinion process: comparison to the Roussel-Uclaf causality assessment method. Hepatology 2010;51:2117-2126. doi: 10.1002/hep.23577.

[16] Lee WM, Hynan LS, Rossaro L, Fontana RJ, Stravitz RT, Larson AM, et al. Intravenous $\mathrm{N}$-acetylcysteine improves transplant-free survival in early stage non-acetaminophen acute liver failure. Gastroenterology 2009;137: 856-864, 864.e1. doi: 10.1053/j.gastro.2009.06.006.

[17] Nabi T, Nabi S, Rafiq N, Shah A. Role of N-acetylcysteine treatment in nonacetaminophen-induced acute liver failure: A prospective study. Saudi J Gastroenterol 2017;23:169-175. doi: 10.4103/1319-3767.207711.

[18] Terrault NA, Lok ASF, McMahon BJ, Chang KM, Hwang JP, Jonas MM, et al. Update on prevention, diagnosis, and treatment of chronic hepatitis $B$ : AASLD 2018 hepatitis B guidance. Hepatology 2018;67:1560-1599. doi: 10.1002/hep.29800.

[19] Wan YM, Li YH, Xu ZY, Wu HM, Xu Y, Wu XN, et al. Tenofovir Versus Entecavir for the Treatment of Acute-on-Chronic Liver Failure due to Reactivation of Chronic Hepatitis B With Genotypes B and C. J Clin Gastroenterol 2019;53: e171-e177. doi: 10.1097/MCG.0000000000001038.

[20] Levitsky J, Duddempudi AT, Lakeman FD, Whitley RJ, Luby JP, Lee WM, et al. Detection and diagnosis of herpes simplex virus infection in adults with acute liver failure. Liver Transpl 2008;14:1498-1504. doi: 10.1002/It.21567.

[21] Little L, Rule J, Peng L, Gottfried M, Lee WM. Herpes simplex virus-associated acute liver failure often goes unrecognized. Hepatology 2019;69:917-919. doi: 10.1002/hep.30236.

[22] Gupta E, Ballani N, Kumar M, Sarin SK. Role of non-hepatotropic viruses in acute sporadic viral hepatitis and acute-on-chronic liver failure in adults. Indian J Gastroenterol 2015;34:448-452. doi: 10.1007/s12664-0150613-0.

[23] Brewer EC, Hunter L. Acute liver failure due to disseminated varicella zoster infection. Case Reports Hepatol 2018;2018:1269340. doi: 10. $1155 / 2018 / 1269340$.

[24] Núñez-Ramos R, Montoro $S$, Bellusci $M$, Del Fresno-Valencia MR, GermánDíaz M, Urruzuno P, et al. Acute liver failure: Outcome and value of pediatric end-stage liver disease score in pediatric cases. Pediatr Emerg Care 2016. doi: $10.1097 /$ PEC.0000000000000884.

[25] Rahim MN, Liberal R, Miquel R, Heaton ND, Heneghan MA. Acute severe autoimmune hepatitis: Corticosteroids or liver transplantation? Liver Transpl 2019;25:946-959. doi: 10.1002/lt.25451.

[26] Roberts EA, Schilsky ML. Diagnosis and treatment of Wilson disease: an update. Hepatology 2008;47:2089-2111. doi: 10.1002/hep.22261.

[27] Korman JD, Volenberg I, Balko J, Webster J, Schiodt FV, Squires RH Jr, et al. Screening for Wilson disease in acute liver failure: a comparison of currently available diagnostic tests. Hepatology 2008;48:1167-1174. doi: 10 . 1002/hep.22446.

[28] Eapen CE, Velissaris D, Heydtmann M, Gunson B, Olliff S, Elias E. Favourable medium term outcome following hepatic vein recanalisation and/or transjugular intrahepatic portosystemic shunt for Budd Chiari syndrome. Gut 2006;55:878-884. doi: 10.1136/gut.2005.071423.

[29] Ye Y, Liu Z. Management of Amanita phalloides poisoning: A literature review and update. J Crit Care 2018;46:17-22. doi: 10.1016/j.jcrc.2018.03.028.

[30] Liu J, Ghaziani TT, Wolf JL. Acute fatty liver disease of pregnancy: Updates in pathogenesis, diagnosis, and management. Am J Gastroenterol 2017;112: 838-846. doi: 10.1038/ajg.2017.54.

[31] Agarwal B, Wright G, Gatt A, Riddell A, Vemala V, Mallett S, et al. Evaluation of coagulation abnormalities in acute liver failure. J Hepatol 2012;57:780786. doi: $10.1016 /$ j.jhep.2012.06.020.

[32] Stravitz RT, Lisman T, Luketic VA, Sterling RK, Puri P, Fuchs M, et al. Minimal effects of acute liver injury/acute liver failure on hemostasis as assessed by thromboelastography. J Hepatol 2012;56:129-136. doi: 10.1016/j.jhep. 2011.04.020.

[33] Pereira SP, Rowbotham D, Fitt S, Shearer MJ, Wendon J, Williams R. Pharmacokinetics and efficacy of oral versus intravenous mixed-micellar phylloquinone (vitamin K1) in severe acute liver disease. J Hepatol 2005;42:365-370. doi: $10.1016 /$ j.jhep.2004.11.030.

[34] West KL, Adamson C, Hoffman M. Prophylactic correction of the international normalized ratio in neurosurgery: a brief review of a brief literature. J Neurosurg 2011;114:9-18. doi: 10.3171/2010.7.JNS091857.

[35] Shami VM, Caldwell SH, Hespenheide EE, Arseneau KO, Bickston SJ, Macik BG. Recombinant activated factor VII for coagulopathy in fulminant hepatic failure compared with conventional therapy. Liver Transpl 2003;9:138-143. doi: $10.1053 /$ jlts.2003.50017.

[36] Le TV, Rumbak MJ, Liu SS, Alsina AE, van Loveren $H$, Agazzi S. Insertion of intracranial pressure monitors in fulminant hepatic failure patients: early experience using recombinant factor VII. Neurosurgery 2010;66:455-458. doi: 10.1227/01.NEU.0000365517.52586.A2.

[37] Pavese P, Bonadona A, Beaubien J, Labrecque P, Pernod G, Letoublon C, et al. FVIIa corrects the coagulopathy of fulminant hepatic failure but may be associated with thrombosis: a report of four cases. Can J Anaesth 2005; 52:26-29. doi: 10.1007/BF03018576.

[38] Stravitz RT, Kramer DJ. Management of acute liver failure. Nat Rev Gastroenterol Hepatol 2009;6:542-553. doi: 10.1038/nrgastro.2009.127.

[39] Etogo-Asse FE, Vincent RP, Hughes SA, Auzinger G, Le Roux CW, Wendon J, et al. High density lipoprotein in patients with liver failure; relation to sepsis, adrenal function and outcome of illness. Liver Int 2012;32:128-136. doi: 10. $1111 / \mathrm{j} .1478-3231.2011 .02657 . x$ 
[40] Eefsen M, Dethloff T, Frederiksen HJ, Hauerberg J, Hansen BA, Larsen FS. Comparison of terlipressin and noradrenalin on cerebral perfusion, intracranial pressure and cerebral extracellular concentrations of lactate and pyruvate in patients with acute liver failure in need of inotropic support. J Hepatol 2007;47:381-386. doi: 10.1016/j.jhep.2007.04.015.

[41] Harry R, Auzinger G, Wendon J. The clinical importance of adrenal insufficiency in acute hepatic dysfunction. Hepatology 2002;36:395-402. doi: 10. 1053/jhep.2002.34514.

[42] Harry R, Auzinger G, Wendon J. The effects of supraphysiological doses of corticosteroids in hypotensive liver failure. Liver Int 2003;23:71-77. doi: 10 . 1034/j.1600-0676.2003.00813.x.

[43] Leithead JA, Ferguson JW, Bates CM, Davidson JS, Lee A, Bathgate AJ, et al. The systemic inflammatory response syndrome is predictive of renal dysfunction in patients with non-paracetamol-induced acute liver failure. Gut 2009;58:443-449. doi: 10.1136/gut.2008.154120.

[44] Tujios SR, Hynan LS, Vazquez MA, Larson AM, Seremba E, Sanders CM, et al. Risk factors and outcomes of acute kidney injury in patients with acute liver failure. Clin Gastroenterol Hepatol 2015;13:352-359. doi: 10.1016/j.cgh. 2014.07.011.

[45] Davenport A, Will EJ, Davidson AM. Improved cardiovascular stability during continuous modes of renal replacement therapy in critically ill patients with acute hepatic and renal failure. Crit Care Med 1993;21:328-338. doi: 10 1097/00003246-199303000-00007.

[46] Vaquero J, Chung C, Cahill ME, Blei AT. Pathogenesis of hepatic encephalopathy in acute liver failure. Semin Liver Dis 2003;23:259-269. doi: 10. 1055/s-2003-42644.

[47] Scott TR, Kronsten VT, Hughes RD, Shawcross DL. Pathophysiology of cerebral oedema in acute liver failure. World J Gastroenterol 2013;19:92409255. doi: 10.3748/wjg.v19.i48.9240.

[48] Reynolds AS, Brush B, Schiano TD, Reilly KJ, Dangayach NS. Neurological Monitoring in Acute Liver Failure. Hepatology 2019;70:1830-1835. doi: 10 1002/hep.30760.

[49] Clemmesen JO, Larsen FS, Kondrup J, Hansen BA, Ott P. Cerebral herniation in patients with acute liver failure is correlated with arterial ammonia concentration. Hepatology 1999;29:648-653. doi: 10.1002/hep.510290309.

[50] Kitzberger R, Funk GC, Holzinger U, Miehsler W, Kramer L, Kaider A, et al. Severity of organ failure is an independent predictor of intracranial hypertension in acute liver failure. Clin Gastroenterol Hepatol 2009; 7:1000-1006. doi: $10.1016 / j . c g h .2009 .05 .019$

[51] Kok B, Karvellas C]. Management of cerebral edema in acute liver failure. Semin Respir Crit Care Med 2017;38:821-829. doi: 10.1055/s-00371608772 .

[52] Wijdicks EF, Nyberg SL. Propofol to control intracranial pressure in fulminan hepatic failure. Transplant Proc 2002;34:1220-1222. doi: 10.1016/s00411345(02)02804-x.

[53] Lele AV, Wilson D, Chalise P, Nazzaro J, Krishnamoorthy V, Vavilala MS. Differences in blood pressure by measurement technique in neurocritically ill patients: A technological assessment. J Clin Neurosci 2018;47:97-102. doi: 10.1016/j.jocn.2017.10.079

[54] Rajaram P, Subramanian R. Management of acute liver failure in the intensive care unit setting. Clin Liver Dis 2018;22:403-408. doi: 10.1016/j.cld.2018. 01.013.

[55] Kandiah PA, Olson JC, Subramanian RM. Emerging strategies for the treatment of patients with acute hepatic failure. Curr Opin Crit Care 2016;22: 142-151. doi: 10.1097/MCC.0000000000000291.

[56] Rajajee V, Fontana RJ, Courey AJ, Patil PG. Protocol based invasive intracranial pressure monitoring in acute liver failure: feasibility, safety and impact on management. Crit Care 2017;21:178. doi: 10.1186/s13054017-1762-6.

[57] Butterworth RF. The concept of "the inflamed brain" in acute liver failure: mechanisms and new therapeutic opportunities. Metab Brain Dis 2016;31: 1283-1287. doi: 10.1007/s11011-015-9747-0.

[58] Bunchorntavakul C, Reddy KR. Acute liver failure. Clin Liver Dis 2017;21: 769-792. doi: 10.1016/j.cld.2017.06.002.

[59] Canalese ], Gimson AE, Davis C, Mellon P], Davis M, Williams R. Controlled trial of dexamethasone and mannitol for the cerebral oedema of fulminant hepatic failure. Gut 1982;23:625-629. doi: 10.1136/gut.23.7.625.

[60] Murphy N, Auzinger G, Bernel W, Wendon J. The effect of hypertonic sodium chloride on intracranial pressure in patients with acute liver failure. Hepatology 2004;39:464-470. doi: 10.1002/hep.20056.

[61] Mpabanzi L, Jalan R. Neurological complications of acute liver failure: pathophysiological basis of current management and emerging therapies. Neurochem Int 2012;60:736-742. doi: 10.1016/j.neuint.2011.10.014.

[62] Karvellas CJ, Todd Stravitz R, Battenhouse H, Lee WM, Schilsky ML. Therapeutic hypothermia in acute liver failure: a multicenter retrospective cohor analysis. Liver Transpl 2015;21:4-12. doi: 10.1002/It.24021.

[63] Jalan R, Olde Damink SW, Deutz NE, Davies NA, Garden O], Madhavan KK, et al. Moderate hypothermia prevents cerebral hyperemia and increase in intracranial pressure in patients undergoing liver transplantation for acute liver failure. Transplantation 2003;75:2034-2039. doi: 10.1097/01.TP. 0000066240.42113.FF.

[64] Munoz SJ. Hypothermia may impair hepatic regeneration in acute liver failure. Gastroenterology 2005;128:1143-1144. doi: $10.1053 / \mathrm{j}$.gastro. 2005.02.048.

[65] García Martínez J], Bendjelid K. Artificial liver support systems: what is new over the last decade? Ann Intensive Care 2018;8:109. doi: 10 1186/s13613-018-0453-z.

[66] Saliba F, Camus C, Durand F, Mathurin P, Letierce A, Delafosse B, et al. Albumin dialysis with a noncell artificial liver support device in patients with acute liver failure: a randomized, controlled trial. Ann Intern Med 2013;159:522-531. doi: 10.7326/0003-4819-159-8-201310150-00005.

[67] Larsen FS, Schmidt LE, Bernsmeier C, Rasmussen A, Isoniemi H, Patel VC, et al. High-volume plasma exchange in patients with acute liver failure: An open randomised controlled trial. J Hepatol 2016;64:69-78. doi: 10.1016/j. jhep.2015.08.018.

[68] Atta HM. Gene therapy for liver regeneration: experimental studies and prospects for clinical trials. World J Gastroenterol 2010;16:4019-4030. doi: 10. 3748/wjg.v16.i32.4019.

[69] Ibars EP, Cortes M, Tolosa L, Gómez-Lechón MJ, López S, Castell JV, et al. Hepatocyte transplantation program: Lessons learned and future strategies. World J Gastroenterol 2016;22:874-886. doi: 10.3748/wjg.v22.i2.874.

[70] Iansante V, Mitry RR, Filippi C, Fitzpatrick E, Dhawan A. Human hepatocyte transplantation for liver disease: current status and future perspectives. Pediatr Res 2018;83:232-240. doi: 10.1038/pr.2017.284.

[71] Simpson KJ, Bates CM, Henderson NC, Wigmore S], Garden OJ, Lee A, et al. The utilization of liver transplantation in the management of acute liver failure: comparison between acetaminophen and non-acetaminophen etiologies. Liver Transpl 2009;15:600-609. doi: 10.1002/It.21681.

[72] Oketani M, Ido A, Nakayama N, Takikawa Y, Naiki T, Yamagishi Y, et al. Etiology and prognosis of fulminant hepatitis and late-onset hepatic failure in Japan: Summary of the annual nationwide survey between 2004 and 2009. Hepatol Res 2013;43:97-105. doi: 10.1111/j.1872-034X.2012.01105.x.

[73] Ichai P, Legeai C, Francoz C, Boudjema K, Boillot O, Ducerf C, et al. Patients with acute liver failure listed for superurgent liver transplantation in France: reevaluation of the Clichy-Villejuif criteria. Liver Transpl 2015;21:512-523. doi: $10.1002 /$ It. 24092

[74] Yoon E, Babar A, Choudhary M, Kutner M, Pyrsopoulos N. Acetaminopheninduced hepatotoxicity: A comprehensive update. J Clin Transl Hepatol 2016 4:131-142. doi: 10.14218/JCTH.2015.00052.

[75] Bernal W, Wang Y, Maggs J, Willars C, Sizer E, Auzinger G, et al. Development and validation of a dynamic outcome prediction model for paracetamolinduced acute liver failure: a cohort study. Lancet Gastroenterol Hepatol 2016;1:217-225. doi: 10.1016/S2468-1253(16)30007-3.

[76] Koch DG, Tillman H, Durkalski V, Lee WM, Reuben A. Development of a model to predict transplant-free survival of patients with acute liver failure. Clin Gastroenterol Hepatol 2016;14:1199-1206.e2. doi: 10.1016/j.cgh.2016. 03.046 .

[77] Craig DG, Zafar S, Reid TW, Martin KG, Davidson JS, Hayes PC, et al. The sequential organ failure assessment (SOFA) score is an effective triage marker following staggered paracetamol (acetaminophen) overdose. Aliment Pharmacol Ther 2012;35:1408-1415. doi: 10.1111/j.1365-2036. 2012.05102.x

[78] Cholongitas E, Theocharidou E, Vasianopoulou P, Betrosian A, Shaw S, Patch D, et al. Comparison of the sequential organ failure assessment score with the King's College Hospital criteria and the model for end-stage liver disease score for the prognosis of acetaminophen-induced acute liver failure. Liver Transpl 2012;18:405-412. doi: 10.1002/It.23370.

[79] McPhail MJ, Farne H, Senvar N, Wendon JA, Bernal W. Ability of king's college criteria and model for end-stage liver disease scores to predict mortality of patients with acute liver failure: A meta-analysis. Clin Gastroenterol Hepatol 2016;14:516-525.e5. doi: 10.1016/j.cgh.2015.10.007

[80] Kumar R, Shalimar, Sharma H, Goyal R, Kumar A, Khanal S, et al. Prospective derivation and validation of early dynamic model for predicting outcome in patients with acute liver failure. Gut 2012;61:1068-1075. doi: 10 . 1136/gutjnl-2011-301762.

[81] Eguchi A, Wree A, Feldstein AE. Biomarkers of liver cell death. J Hepatol 2014;60:1063-1074. doi: 10.1016/j.jhep.2013.12.026.

[82] Rutherford A, King LY, Hynan LS, Vedvyas C, Lin W, Lee WM, et al. Development of an accurate index for predicting outcomes of patients with acute liver failure. Gastroenterology 2012;143:1237-1243. doi: 10.1053/j.gastro. 2012.07.113.

[83] Bechmann LP, Jochum C, Kocabayoglu P, Sowa JP, Kassalik M, Gieseler RK, et al. Cytokeratin 18-based modification of the MELD score improves prediction of spontaneous survival after acute liver injury. J Hepatol 2010;53:639647. doi: 10.1016/j.jhep.2010.04.029.

[84] Antoniades CG, Berry PA, Davies ET, Hussain M, Bernal W, Vergani D, et al. Reduced monocyte HLA-DR expression: a novel biomarker of disease severity and outcome in acetaminophen-induced acute liver failure. Hepatology 2006;44:34-43. doi: 10.1002/hep.21240 
Seetharam A.: Liver transplantation for acute liver failure

[85] O'Grady J. Liver transplantation for acute liver failure. Best Pract Res Clin Gastroenterol 2012;26:27-33. doi: 10.1016/j.bpg.2012.01.012.

[86] Samuel D, Saliba F, Ichai P. Changing outcomes in acute liver failure: Can we transplant only the ones who really need it? Liver Transpl 2015;21 Suppl 1: S36-S38. doi: 10.1002/It.24310.

[87] Carrion AF, Martin P. Non-intensive care unit management of acute liver failure. Clin Liver Dis 2018;22:389-401. doi: 10.1016/j.cld.2018.01.009.

[88] Organ Procurement and Transplantation Network (OPTN) Policies. Available from: https://optn.transplant.hrsa.gov/media/1200/optn_policies.pdf.

[89] Farmer DG, Anselmo DM, Ghobrial RM, Yersiz H, McDiarmid SV, Cao C, et al. Liver transplantation for fulminant hepatic failure: experience with more than 200 patients over a 17-year period. Ann Surg 2003;237:666-675. doi: 10.1097/01.SLA.0000064365.54197.9E.

[90] Freeman RB Jr, Steffick DE, Guidinger MK, Farmer DG, Berg CL, Merion RM. Liver and intestine transplantation in the United States, 1997-2006. Am J Transplant 2008;8:958-976. doi: 10.1111/j.1600-6143.2008.02174.x.

[91] O'Grady J. Timing and benefit of liver transplantation in acute liver failure. J Hepatol 2014;60:663-670. doi: 10.1016/j.jhep.2013.10.024.

[92] Barshes NR, Lee TC, Balkrishnan R, Karpen SJ, Carter BA, Goss JA. Risk stratification of adult patients undergoing orthotopic liver transplantation for fulminant hepatic failure. Transplantation 2006;81:195-201. doi: 10 . 1097/01.tp.0000188149.90975.63. 